\title{
Influence of intranasal and carotid cooling on cerebral temperature balance and oxygenation
}

\author{
Lars $\mathrm{Nybo}^{1 *}$, Michael Wanscher ${ }^{2}$ and Niels H. Secher ${ }^{3}$ \\ ${ }^{1}$ Department of Nutrition, Exercise and Sport Sciences, University of Copenhagen, Copenhagen, Denmark \\ ${ }^{2}$ Department of Cardiothoracic Anaesthesia, Copenhagen University Hospital Rigshospitalet, Copenhagen, Denmark \\ ${ }^{3}$ Copenhagen Muscle Research Center, Department of Anaesthesia, Rigshospitalet, University of Copenhagen, Copenhagen, Denmark
}

Edited by:

Phil N. Ainslie, University of British

Columbia, Canada

Reviewed by:

Phil N. Ainslie, University of British

Columbia, Canada

Anthony R. Bain, University of

British Columbia, Canada

*Correspondence:

Lars Nybo, Section of Human

Physiology, Department of Nutrition,

Exercise and Sport Sciences,

University of Copenhagen,

Universitetsparken 13, DK-2100

Copenhagen $\varnothing$, Denmark

e-mail: Innielsen@ifi.ku.dk
The present study evaluated the influence of intranasal cooling with balloon catheters, increased nasal ventilation, or percutaneous cooling of the carotid arteries on cerebral temperature balance and oxygenation in six healthy male subjects. Aortic arch and internal jugular venous blood temperatures were measured to assess the cerebral heat balance and corresponding paired blood samples were obtained to evaluate cerebral metabolism and oxygenation at rest, following $60 \mathrm{~min}$ of intranasal cooling, $5 \mathrm{~min}$ of nasal ventilation, and $15 \mathrm{~min}$ with carotid cooling. Intranasal cooling induced a parallel drop in jugular venous and arterial blood temperatures by $0.30 \pm 0.08^{\circ} \mathrm{C}$ (mean $\pm \mathrm{SD}$ ), whereas nasal ventilation and carotid cooling failed to lower the jugular venous blood temperature. The magnitude of the arterio-venous temperature difference across the brain remained unchanged at $-0.33 \pm 0.05^{\circ} \mathrm{C}$ following intranasal and carotid cooling, but increased to $-0.44 \pm 0.11^{\circ} \mathrm{C}(P<0.05)$ following nasal ventilation. Calculated cerebral capillary oxygen tension was $43 \pm 3 \mathrm{mmHg}$ at rest and remained unchanged during intranasal and carotid cooling, but decreased to $38 \pm 2 \mathrm{mmHg}(P<0.05)$ following increased nasal ventilation. In conclusion, percutaneous cooling of the carotid arteries and intranasal cooling with balloon catheters are insufficient to influence cerebral oxygenation in normothermic subjects as the cooling rate is only $0.3^{\circ} \mathrm{C}$ per hour and neither intranasal nor carotid cooling is capable of inducing selective brain cooling.

Keywords: balloon catheter, brain temperature, cerebral oxygenation, cooling, hypothermia

\section{INTRODUCTION}

Cooling of the brain is of relevance for preventing cerebral ischemia during anesthesia and after cardiac arrest hypothermia may improve neurological outcome and even survival (Hoesch and Geocadin, 2007; Holzer, 2008, 2013; Lay and Badjatia, 2010; Harris et al., 2012). Cerebral cooling can be induced by global lowering of the body temperature as arterial blood will gradually lower brain temperature (Nybo et al., 2002; Holzer, 2008). However, methods have been developed in attempt to selectively cool the brain, i.e., without affecting other parts of the body (for review see Harris et al., 2012) in order to attenuate the risk of, e.g., pneumonia and sepsis (Geurts et al., 2014). Selective-brain cooling is defined as a lowering of the average brain temperature to below that of arterial blood as observed in several animal species including mammals with a carotid rete (Jessen, 2001). Whether humans, despite the lack of a carotid rete, have the ability to selectively cool their brain remains controversial (Brengelmann, 1993; Cabanac, 1993; White et al., 2010), but is probably unlikely under normal circumstances (Nybo et al., 2002; Maloney et al., 2007; Nybo and Secher, 2011). Yet, various intranasal cooling techniques have been developed (Harris et al., 2012) and Covaciu et al. (2011) report from a magnetic resonance (MR) spectroscopic-based evaluation of cerebral temperature that intranasal cooling with balloon catheter induced a rapid and substantial lowering of the brain temperature. Springborg et al. (2013) also find that intranasal cooling lowers cerebral temperature in hyperthermic brain-injured patients. However, in contrast to the observations presented by Covaciu et al. (2011), Springborg et al. (2013) report brain cooling to take place in parallel with normalization of the core temperature in their hyperthermic patients. Hence, it remains unclear whether intranasal cooling can induce selective brain cooling and to what extend it lowers brain temperature in normothermic subjects and thereby influences the cerebral metabolic rate and its oxygenation.

Cooling of the carotid arteries, either by percutaneous cooling of the neck or through augmented heat release from upper respiratory airway induced by increased ventilation could influence the temperature of arterial blood entering the brain (Rasch et al., 1991). As demonstrated during exercise, hyperpnea lowers tissue temperature adjacent to the carotid arteries and could thereby narrow the arterio-venous temperature difference across the brain (Nybo et al., 2002). However, in resting subjects the effect of increased nasal ventilation on brain temperature is not clear. Therefore, the present study was conducted to evaluate the effects of intranasal cooling, percutaneous cooling of the carotid arteries, and nasal ventilation on cerebral temperature balance and oxygenation.

\section{MATERIALS AND METHODS}

Six healthy male subjects at a mean age of $30 \pm 4$ years $( \pm$ SD), height of $185 \pm 5 \mathrm{~cm}$ and weight $79 \pm 8 \mathrm{~kg}$ participated in the study as approved by the local ethics committee (protocol 
H-4-2010-081) and conducted in accordance to the Declaration of Helsinki.

The subjects arrived at the laboratory in the morning $\sim 1 \mathrm{~h}$ before the start of the experiment and were instrumented with thermocouples to record forehead, cheek, and neck (over the left carotid artery) skin temperature (Ellab, Copenhagen, Denmark) an ultra sound transcranial Doppler probe, and a heart rate (HR) monitor. Then, the subjects were provided with a $18 \mathrm{G}$ catheter ( $32 \mathrm{~mm}$; BD A/S, Denmark) in the brachial artery of the nondominant arm and, under local anesthesia, a $5 \mathrm{~F}$ Swan-Ganz catheter (Edwards; USA) was placed in the right internal jugular vein and advanced to the bulb of the vein. A thermocouple (model MAC-07170-A, Ellab) was inserted via the arterial catheter and advanced to the aortic arch to record arterial temperature (Nybo et al., 2002), while the internal jugular venous blood temperature was obtained from the temperature sensor positioned at the bulb of the internal jugular vein. Furthermore, intra-nasal temperature was measured $1 \mathrm{~cm}$ into the nostrils with a thin thermocouple (MHA model, Ellab, Copenhagen, Denmark) inserted for 2 min (and until the measure was stable) with the tip/electrode directed outward; i.e., during the nasal cooling period into the tissue and away from the balloon catheter.

Simultaneous blood samples were obtained from the two catheters at baseline (after $45 \mathrm{~min}$ of supine rest), following $1 \mathrm{~h}$ of intra-nasal cooling, following $15 \mathrm{~min}$ of carotid cooling, and at the end of a $5 \mathrm{~min}$ period with increased nasal ventilation during which the subjects were instructed to double their ventilation and inhale exclusively through the nose and exhale through the mouth. All blood samples were immediately analyzed for $\mathrm{PO}_{2}, \mathrm{PCO}_{2}$, oxygen saturation, hemoglobin, glucose, and lactate (ABL 800, Radiometer, Copenhagen, Denmark). Cerebral arteriovenous differences for oxygen $\left(\mathrm{a}-\mathrm{vDO}_{2}\right)$, glucose $(\mathrm{a}-\mathrm{vD}$ glucose $)$, and lactate $\left(\mathrm{a}-\mathrm{v} \mathrm{D}_{\text {lactate }}\right)$ were determined on basis of paired blood samples. Furthermore, changes in mean cerebral capillary oxygen saturation and capillary oxygen tension were calculated according to Rasmussen et al. (2006) with the assumption that oxygen extraction rises linearly with distance as blood traverses the capillary network from the arterial to venous end, and the average capillary bed satisfy coequal amounts of brain tissue.

Middle cerebral artery mean blood velocity (MCA $\left.\mathrm{V}_{\text {mean }}\right)$ was monitored by transcranial Doppler (Transcan, EME, Überlingen, Germany) to estimate changes in cerebral blood flow (CBF). The best signal-noise ratio at the proximal part of the MCA was selected and the vessel was insonated at a depth of $\sim 50 \mathrm{~mm}$ with the probe secured with a headband. MCA $\mathrm{V}_{\text {mean }}$ was computed from the integral of the maximum frequency Doppler shifts over each heartbeat and the average from 2 min was determined for rest, nasal cooling, carotid cooling, and nasal ventilation. It was assumed that the diameter of the insonated vessel remains unchanged across the evaluated conditions. Serrador et al. (2000) found no variation in vessel diameter with changes in $\mathrm{P}_{\mathrm{a}} \mathrm{CO}_{2}$ and it appears that the $\mathrm{CBF}$ is regulated distal to the proximal part of MCA, although some effect of $\mathrm{P}_{\mathrm{a}} \mathrm{CO}_{2}$ on vessel diameter cannot be excluded (Valdueza et al., 1999). However, changes in MCA velocity correlate with those in ${ }^{133}$ Xenon determined CBF (Jørgensen, 1995) and we estimated changes in CBF from the percentage change in MCA $\mathrm{V}_{\text {mean }}$.

\section{COOLING INTERVENTIONS}

The intra-nasal cooling was applied via two single-use intranasal balloon catheters (QuickCool Disposable Balloon Catheter, QuickCool AB, Lund, Sweden) perfused with cold isotonic saline from a heat exchanger in a closed circuit system (ComVic, QuickCool AB, Lund, Sweden). The pressure in the balloons was maintained between 20 and $30 \mathrm{mmHg}$ and flow exchange was set to $200 \mathrm{ml}$ per min with the temperature in the heat exchanger at $1^{\circ} \mathrm{C}$. The cooling period was $1 \mathrm{~h}$ and all six subjects tolerated and completed the entire period without any adverse effects.

Nasal ventilation was initiated $2 \mathrm{~min}$ after removal of the balloon catheters in attempt to increase cooling of the upper respiratory airways while the tissue in the nasal sinuses was low.

The subject was instructed to inhale forcefully through the nose and exhale via the mouth for 5 min to maximize the potential cooling effects and that was accomplished by all subjects. Blood samples were drawn and temperatures registered during the last $30 \mathrm{~s}$ of the $5 \mathrm{~min}$ intervention. Following the nasal ventilation test, the subject rested for at least $45 \mathrm{~min}$ or until arterial blood temperature and $\mathrm{P}_{\mathrm{a}} \mathrm{CO}_{2}$ had returned to baseline values. Thereafter $15 \mathrm{~min}$ of carotid cooling was applied by placing ice packets on both sides of the neck $(\sim 10 \mathrm{~cm}$ long and $5 \mathrm{~cm}$ thick plastic bag filled with crushes ice and wrapped in a thin piece of fabric to avoid freezing the skin). One subject however tolerated this intervention for only $10 \mathrm{~min}$, but developed a similar drop in skin temperature as the other five subjects.

\section{STATISTICAL ANALYSIS}

Values are presented as mean \pm SD unless otherwise indicated. Changes over time, i.e., during the period with nasal cooling or across conditions (baseline, intra-nasal cooling, nasal ventilation and carotid cooling) were evaluated with repeated One-Way ANOVA and the significance level was set at $P<0.05$. In case of a significant difference across conditions, a Tukey post-hoc test with Bonferroni correction was used to identify differences.

\section{RESULTS}

There was a small but significant decline in internal jugular venous blood temperature during the $1 \mathrm{~h}$ period with nasal cooling (Figure 1) occurring in parallel with the drop in body temperature as the arterio-venous temperature difference across the brain remained unchanged at $-0.33 \pm 0.05^{\circ} \mathrm{C}$. Furthermore, the arterio-venous temperature difference across the brain was not changed during carotid cooling, whereas it was widened to $-0.44 \pm 0.11^{\circ} \mathrm{C}$ following the period with nasal ventilation. Thus, the jugular venous blood temperature remained in the range $0.3-0.44^{\circ} \mathrm{C}$ above that of the arterial blood despite marked reductions in intranasal, neck, and face skin temperatures as illustrated in Figure 2.

MCA $\mathrm{V}_{\text {mean }}$ remained unchanged (within $2 \%$ of baseline values) during intranasal and carotid cooling, whereas it declined to $45 \pm 7 \%$ of the baseline value at the end of the $5 \mathrm{~min}$ period with nasal ventilation. Accordingly, $\mathrm{PaCO}_{2}$ was similar at baseline $(39.2 \pm 0.7 \mathrm{mmHg})$ during intra-nasal $(39.1 \pm 0.9 \mathrm{mmHg})$ and carotid cooling $(39.5 \pm 0.9 \mathrm{mmHg})$, but declined to $20.9 \pm$ $3.2 \mathrm{mmHg}$ following $5 \mathrm{~min}$ of nasal ventilation. Furthermore, $\mathrm{PaO}_{2}$ and saturation were similar at baseline, following intranasal 


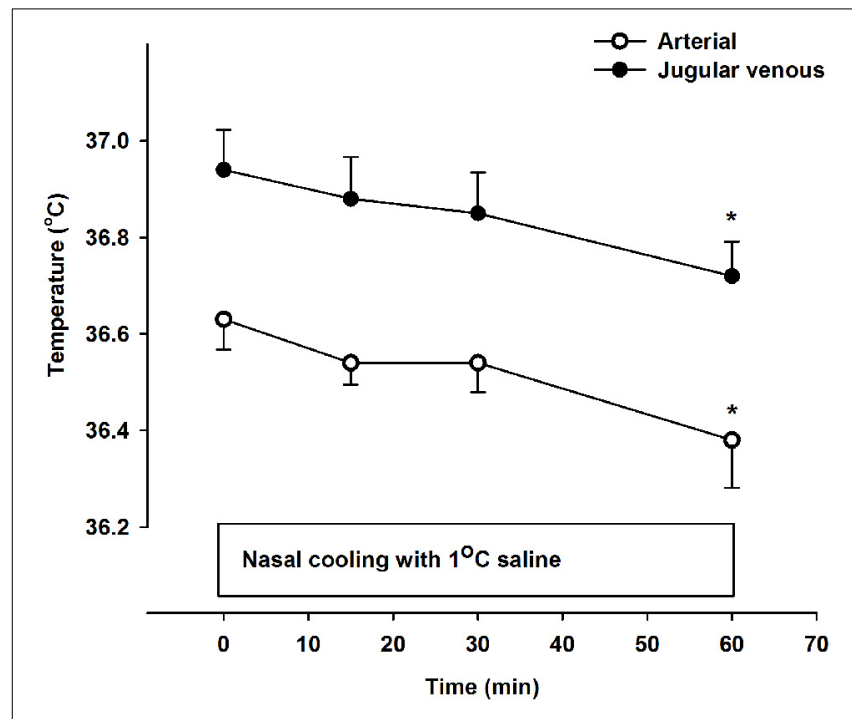

FIGURE 1 | Arterial (open symbols) and jugular venous blood temperature (filled symbols) at rest $(0 \mathrm{~min})$ and during $60 \mathrm{~min}$ of nasal cooling with $1^{\circ} \mathrm{C}$ saline circulated through the nasal catheters at a flow rate of $200 \mathrm{ml} / \mathbf{m i n}$. *Signifies that the value is lower compared to corresponding value at $0 \mathrm{~min}(P<0.05)$. The jugular venous blood temperature was significantly higher than that of the arterial blood at all time points $(P<0.001)$.

and carotid cooling (average $\mathrm{PaO}_{2} \sim 100 \mathrm{mmHg}$ and saturation $\sim 97.5 \%$ ), but increased to $125.1 \pm 3.7 \mathrm{mmHg}$ and $99.6 \pm$ $0.2 \%$ following the $5 \mathrm{~min}$ period with increased nasal ventilation

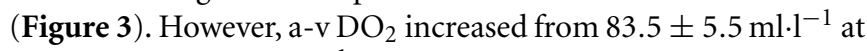
rest to $119.1 \pm 7.0 \mathrm{ml} \cdot \mathrm{l}^{-1}$ following the nasal ventilation period and the jugular venous and mean cerebral capillary oxygen tension were lowered by $\sim 10$ and $5 \mathrm{mmHg}$, respectively. In contrast, a-v $\mathrm{DO}_{2}$, jugular venous $\mathrm{PO}_{2}$ and mean cerebral capillary oxygen tension remained unchanged following intranasal and carotid cooling (Figure 3, lower panel). Also, a-vD glucose was similar at rest, following intranasal, and carotid cooling with an average of $0.55 \pm 0.08 \mathrm{mmol} \cdot \mathrm{l}^{-1}$ and the cerebral release of lactate remained low with an a-vDlactate of $-0.05 \pm 0.03 \mathrm{mmol} \cdot \mathrm{l}^{-1}$. In contrast, a$\mathrm{vD}_{\text {glucose }}$ increased to $1.04 \pm 0.16 \mathrm{mmol} \cdot \mathrm{l}^{-1}$ and a-vDlactate was widened to $-0.20 \pm 0.07 \mathrm{mmol} \cdot \mathrm{l}^{-1}$ following the period with nasal ventilation.

\section{DISCUSSION}

The present study shows that intranasal cooling may lower the cerebral venous blood temperature indicating that the technique is capable of affecting the average brain tissue temperature. However, the cooling was modest and related to body core cooling and intranasal cooling did not selectively cool the brain. In the studied healthy normothermic subjects, the cooling rate was $0.3^{\circ} \mathrm{C}$ per hour and insufficient to influence cerebral oxygenation following $60 \mathrm{~min}$. In addition, neither nasal ventilation nor carotid cooling was capable of providing a significant lowering of the cerebral venous blood temperature and also failed to increase cerebral capillary oxygenation. On the basis of these observations we conclude that intranasal cooling with balloon catheters is not recommendable for rapid cooling of the brain or

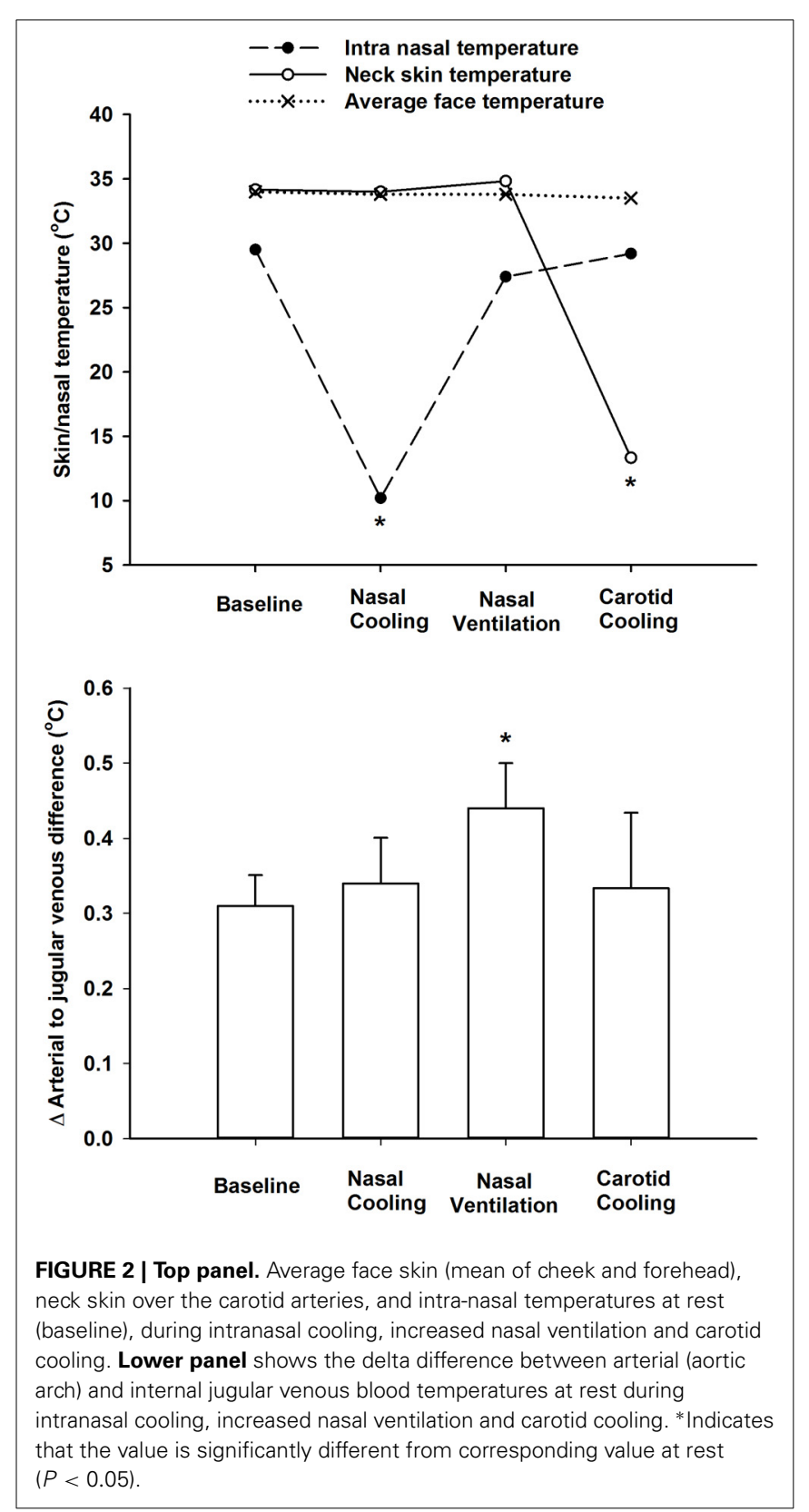

to improve cerebral oxygenation and it does not selectively cool the brain.

The cerebral cooling rate achieved with intranasal cooling was comparable to that reported by other head cooling device applications in normothermic subjects (Koehn et al., 2012; Poli et al., 2013), but the rate was somewhat lower than that obtained in hyperthermic (Abou-Chebl et al., 2011; Springborg et al., 2013) and normothermic stroke patients (Poli et al., 2014) with intranasal cooling. Also the cerebral cooling was substantially slower than the rates obtained in normothermic patients with cooling induced via veno-venous extracorporeal circulation which may lower the arterial blood and brain temperatures in parallel with cooling rates of $\sim 3.5^{\circ} \mathrm{C}$ per hour (Piepgras et al., 1998) or even faster (Testori et al., 2013). That the cerebral cooling 


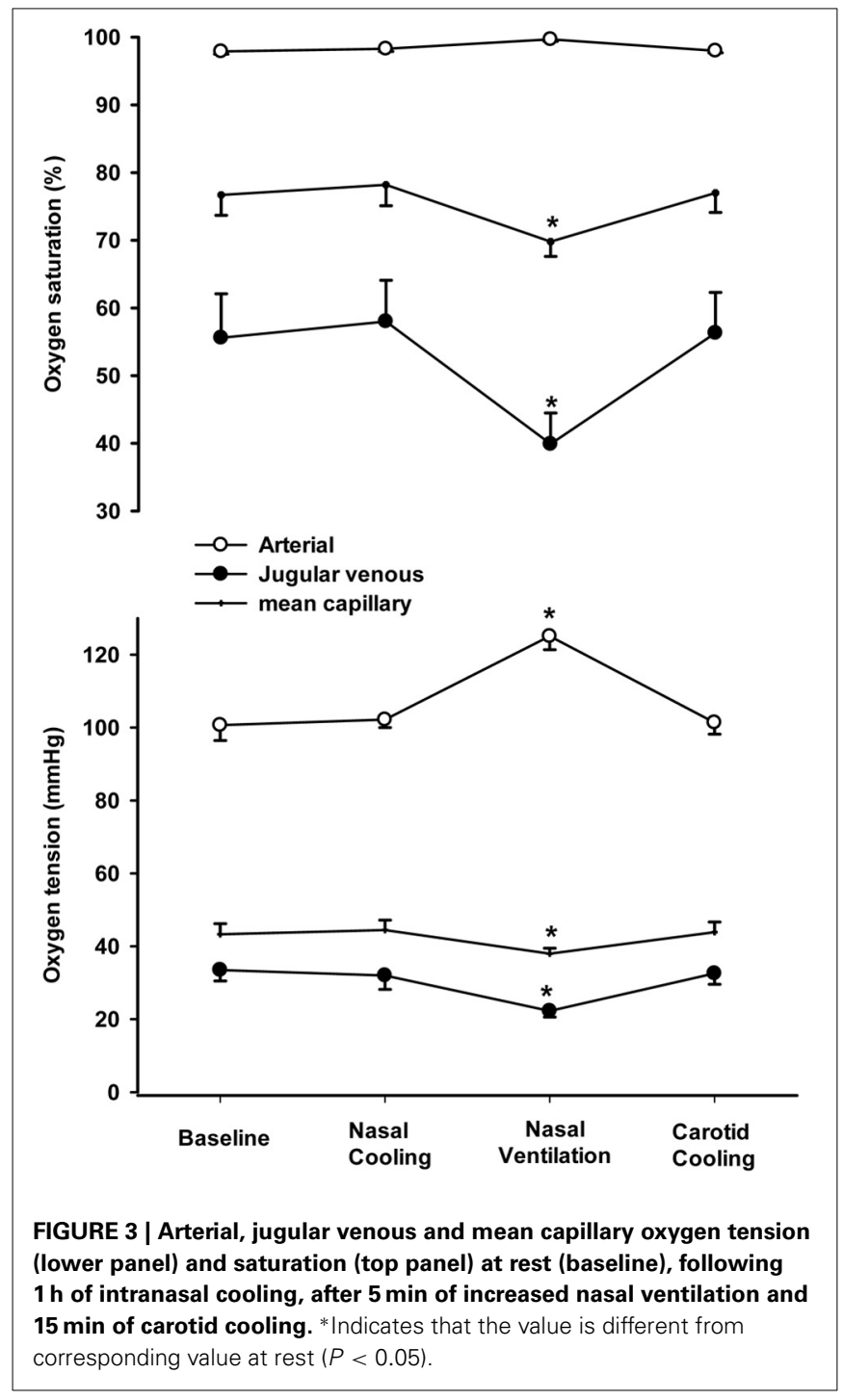

induced via intranasal cooling relates to general body core cooling and not to selective brain cooling is in accordance with the observations by Springborg et al. (2013) in hyperthermic braininjured comatic patients. In contrast, Covaciu et al. (2011) report that the balloon catheter method we used with intra-nasal cooling induced a drop in brain temperature which exceeded the decline in rectal temperature indicating that the method could introduce semi-selective cooling of the brain. However, while we tracked changes in cerebral temperature by a continuous measure of the cerebral venous blood temperature and Springborg et al. (2013) measured brain temperature directly, Covaciu et al. (2011) evaluated brain temperature changes using MR spectroscopic imaging and they tracked changes in body core temperature by measures of rectal temperature that responds only slowly to changes in core temperature (Nielsen and Nielsen, 1962). Thus, methodological differences may explain the discrepancy between observations.

The $\mathrm{Q}_{10}$ effect on the cerebral metabolic rate for oxygen is $\sim 2$ (Klementavicius et al., 1996; Nybo et al., 2002). Considering, the modest cooling of $\sim 0.3$ degrees achieved in the present study and the unchanged $\mathrm{CBF}$ and $\mathrm{P}_{a} \mathrm{O}_{2}$ it seems reasonable that the cerebral oxygenation remained unchanged following the $60 \mathrm{~min}$ period with intranasal cooling or following the carotid cooling. The increased nasal ventilation immediately following the nasal cooling was introduced in attempt to increase the heat release from the upper respiratory track that has been hypothesized to influence brain temperature (Rasch et al., 1991; Mariak et al., 1999). However, increased heat release from the brain was presumably not established following nasal ventilation as MCA $\mathrm{V}_{\text {mean }}$ declined by more than $50 \%$ indicating a marked lowering of $\mathrm{CBF}$ in the hypocapnic condition. Heat release from the brain is determined by the product of the arterio-venous temperature difference across the brain, $\mathrm{CBF}$ and the specific heat capacity of blood (Nybo et al., 2002) and although the present data do not allow for calculation of the cerebral heat balance, a marked lowering of CBF would outweigh the increased blood temperature difference across the brain following the period with nasal hyperventilation. Furthermore, the hyperventilationinduced hypocapnia was associated with increased lactate release from the brain indicating that reduced $\mathrm{CBF}$ and consequently lower cerebral oxygen delivery may have compromised aerobic metabolism and we observed that the mean capillary and venous oxygen tension were reduced following the period with nasal ventilation. All subjects tolerated the $5 \mathrm{~min}$ period with nasal ventilation without reporting signs of dizziness, but the hypocapnic level and marked reduction in MCA $\mathrm{V}_{\text {mean }}$ indicate that they were close to levels that may lead to syncope (Immink et al., in press). If normal alveolar ventilation and consequently also $\mathrm{P}_{a} \mathrm{CO}_{2}$ had been maintained during the nasal ventilation, it is almost certain that cerebral oxygenation had also remained stable, however, we asked the subjects to inhale forcefully through the nose to maximize the potential cooling effects this could have on the upper respiratory tract. Therefore, hyperventilation-induced hypocapnia was introduced and the associated lowering of cerebral oxygen delivery was expected (Kety and Schmidt, 1948) during this part of the experiment targeted at optimizing cooling and not at enhancing the cerebral oxygenation.

\section{CONCLUDING REMARKS}

Intranasal cooling with balloon catheters was insufficient to influence the cerebral oxygenation in awake, healthy subjects. The cooling procedure lowered the temperature within the nasal cavity by $\sim 20^{\circ} \mathrm{C}$ but the effect on the cerebral temperature was modest with an estimated cooling rate of $0.3^{\circ} \mathrm{C}$ per hour and the cooling was not selective for the brain as the arterio-venous temperature difference across the brain remained unchanged. In addition, neither nasal ventilation nor bilateral percutaneous cooling of the carotid arteries was capable of providing significant lowering of the cerebral venous blood temperature and these methods also failed to increase cerebral capillary oxygenation.

\section{AUTHOR CONTRIBUTIONS}

Lars Nybo designing, planning and conducting the experiments, analysis of data and writing the manuscript; Michael Wanscher designing, planning and conducting the experiments and contributing to the manuscript; Niels H. Secher designing, planning and conducting the experiments and contributing to the manuscript 


\section{ACKNOWLEDGMENTS}

The authors would like to thank the subjects for their time and effort and the Danish Ministry of Culture for supporting the studies.

\section{REFERENCES}

Abou-Chebl, A., Sung, G., Barbut, D., and Torbey, M. (2011). Local brain temperature reduction through intranasal cooling with the RhinoChill device: preliminary safety data in brain-injured patients. Stroke 42, 2164-2169. doi: 10.1161/STROKEAHA.110.613000

Brengelmann, G. L. (1993). Specialized brain cooling in humans? FASEB J. 7, 1148-1153.

Cabanac, M. (1993). Selective brain cooling in humans: "fancy" or fact? FASEB J. 7, 1143-1146.

Covaciu, L., Weis, J., Bengtsson, C., Allers, M., Lunderquist, A., Ahlstrom, H., et al. (2011). Brain temperature in volunteers subjected to intranasal cooling. Int. Care Med. 37, 1277-1284. doi: 10.1007/s00134-011-2264-7

Geurts, M., MacLeod, M. R., Kollmar, R., Kremer, P. H., and van der Worp, H. B. (2014). Therapeutic hypothermia and the risk of infection: a systematic review and meta-analysis. Crit. Care Med. 42, 231-242. doi: 10.1097/CCM.0b013e3182 a276e 8

Harris, B., Andrews, P. J., Murray, G. D., Forbes, J., and Moseley, O. (2012). Systematic review of head cooling in adults after traumatic brain injury and stroke. Health Technol. Assess. 16, 1-175. doi: 10.3310/hta16450

Hoesch, R. E., and Geocadin, R. G. (2007). Therapeutic hypothermia for global and focal ischemic brain injury - a cool way to improve neurologic outcomes. Neurologist 13, 331-342. doi: 10.1097/NRL.0b013e318154bb79

Holzer, M. (2008). Devices for rapid induction of hypothermia. Eur. J. Anaesthesiol. Suppl. 42, 31-38. doi: 10.1017/S0265021507003274

Holzer, M. (2013). Therapeutic hypothermia following cardiac arrest. Best Pract. Res. Clin. Anaesthesiol. 27, 335-346. doi: 10.1016/j.bpa.2013.07.003

Immink, R. V., Pott, F., Secher, N. H., and van Lieshout, J. J. (in press). Hyperventilation, cerebral perfusion and syncope. J. Appl. Physiol. doi: 10.1152/japplphysiol.00637.2013

Jessen, C. (2001). Selective brain cooling in mammals and birds. Jpn. J. Physiol. 51, 291-301. doi: 10.2170/jjphysiol.51.291

Jørgensen, L. (1995). Transcranial Doppler ultrasound for cerebral perfusion. Acta Physiol. Scand. 154(Suppl. 625), 1-44.

Kety, S., and Schmidt, C. (1948). The effects of altered arterial tensions of carbon dioxide and oxygen on cerebral blood flow and cerebral oxygen consumption of normal young men. J. Clin. Invest. 27, 484-492. doi: 10.1172/JCI101995

Klementavicius, R., Nemoto, E. M., and Yonas, H. (1996). The Q 10 ratio for basal cerebral metabolic rate of oxygen in rats. J. Neurosurg. 85, 482-487. doi: 10.3171/jns.1996.85.3.0482

Koehn, J., Kollmar, R., Cimpianu, C. L., Kallmunzer, B., Moeller, S., Schwab, S., et al. (2012). Head and neck cooling decreases tympanic and skin temperature, but significantly increases blood pressure. Stroke 43, 2142-2148. doi: 10.1161/STROKEAHA.112.652248

Lay, C., and Badjatia, N. (2010). Therapeutic hypothermia after cardiac arrest. Curr. Atheroscler. Rep. 12, 336-342. doi: 10.1007/s11883-010-0119-2

Maloney, S. K., Mitchell, D., Mitchell, G., and Fuller, A. (2007). Absence of selective brain cooling in unrestrained baboons exposed to heat. Am. J. Physiol. Regul. Integr. Comp. Physiol. 292, R2059-R2067. doi: 10.1152/ajpregu.00809.2006

Mariak, Z., White, M. D., Lewko, J., Lyson, T., and Piekarski, P. (1999). Direct cooling of the human brain by heat loss from the upper respiratory tract. J. Appl. Physiol. 87, 1609-1613.

Nielsen, B., and Nielsen, M. (1962). Body temperature during work at different environmental temperatures. Acta Physiol. Scand. 56, 120-129. doi: 10.1111/j.1748-1716.1962.tb02489.x
Nybo, L., and Secher, N. H. (2011). Counterpoint: humans do not demonstrate selective brain cooling during hyperthermia. J. Appl. Physiol. 110, 571-573. doi: 10.1152/japplphysiol.00992.2010a

Nybo, L., Secher, N. H., and Nielsen, B. (2002). Inadequate heat release from the human brain during prolonged exercise with hyperthermia. J. Physiol. 545, 697-704. doi: 10.1113/jphysiol.2002.030023

Piepgras, A., Roth, H., Schurer, L., Tillmans, R., Quintel, M., Herrmann, P., et al. (1998). Rapid active internal core cooling for induction of moderate hypothermia in head injury by use of an extracorporeal heat exchanger. Neurosurgery 42 , 311-317. doi: 10.1097/00006123-199802000-00058

Poli, S., Purrucker, J., Priglinger, M., Diedler, J., Sykora, M., Popp, E., et al. (2013). Induction of cooling with a passive head and neck cooling device: effects on brain temperature after stroke. Stroke 44, 708-713. doi: 10.1161/STROKEAHA.112.672923

Poli, S., Purrucker, J., Priglinger, M., Sykora, M., Diedler, J., Rupp, A., et al. (2014). Safety evaluation of nasopharyngeal cooling (RhinoChill) in stroke patients: an observational study. Neurocrit. Care 20, 98-105. doi: 10.1007/s12028-0139904-4

Rasch, W., Samson, P., Cote, J., and Cabanac, M. (1991). Heat loss from the human head during exercise. J. Appl. Physiol. 71, 590-595.

Rasmussen, P., Dawson, E. A., Nybo, L., van Lieshout, J. J., Secher, N. H., and Gjedde, A. (2006). Capillary-oxygenation-level-dependent near-infrared spectrometry in frontal lobe of humans. J. Cereb. Blood Flow Metab. 27, 1082-1093. doi: $10.1038 /$ sj.jcbfm.9600416

Serrador, J. M., Picot, P. A., Rutt, B. K., Shoemaker, J. K., and Bondar, R. L. (2000). MRI measures of middle cerebral artery diameter in conscious humans during simulated orthostasis. Stroke 31, 1672-1678. doi: 10.1161/01. STR.31.7.1672

Springborg, J. B., Springborg, K. K., and Romner, B. (2013). First clinical experience with intranasal cooling for hyperthermia in brain-injured patients. Neurocrit. Care 18, 400-405. doi: 10.1007/s12028-012-9806-x

Testori, C., Holzer, M., Sterz, F., Stratil, P., Hartner, Z., Moscato, F., et al. (2013). Rapid induction of mild therapeutic hypothermia by extracorporeal veno-venous blood cooling in humans. Resuscitation 84, 1051-1055. doi: 10.1016/j.resuscitation.2013.03.013

Valdueza, J. M., Draganski, B., Hoffmann, O., Dirnagl, U., and Einhaupl, K. M. (1999). Analysis of CO2 vasomotor reactivity and vessel diameter changes by simultaneous venous and arterial Doppler recordings. Stroke 30, 81-86. doi: 10.1161/01.STR.30.1.81

White, M. D., Greiner, J. G., and McDonald, P. L. (2010). Point: counterpoint "Humans do/do not demonstrate selective brain cooling during hyperthermia." J. Appl. Physiol. 110, 569-571. doi: 10.1152/japplphysiol.00992.2010

Conflict of Interest Statement: The authors declare that the research was conducted in the absence of any commercial or financial relationships that could be construed as a potential conflict of interest.

Received: 12 November 2013; paper pending published: 27 January 2014; accepted: 07 February 2014; published online: 27 February 2014

Citation: Nybo L, Wanscher M and Secher NH (2014) Influence of intranasal and carotid cooling on cerebral temperature balance and oxygenation. Front. Physiol. 5:79. doi: 10.3389/fphys.2014.00079

This article was submitted to Integrative Physiology, a section of the journal Frontiers in Physiology.

Copyright (C) $2014 \mathrm{Nybo}$, Wanscher and Secher. This is an open-access article distributed under the terms of the Creative Commons Attribution License (CC BY). The use, distribution or reproduction in other forums is permitted, provided the original author(s) or licensor are credited and that the original publication in this journal is cited, in accordance with accepted academic practice. No use, distribution or reproduction is permitted which does not comply with these terms. 